\title{
“Are multichannel customers really more valuable? An analysis of banking services"
}

\section{Authors $(*)$}

\section{1.-Jesús Cambra-Fierro}

Management and Marketing Department

University Pablo de Olavide, Sevilla , Spain

jjcamfie@upo.es

\section{2.-Wagner A. Kamakura}

Jesse H Jones Professor of Marketing

Rice University, Houston, TX, EEUU

kamakura@rice.edu

\section{3.-Iguacel Melero-Polo}

Department of Marketing

University of Zaragoza, Spain

imelero@unizar.es

\section{4.-F. Javier Sese}

Department of Marketing

University of Zaragoza, Spain

javisese@unizar.es

(*) The name of the authors appear in alphabetical order. Jesus Cambra-Fierro, Iguacel MeleroPolo, and F. Javier Sese are members of the research group Generes (http://generes.unizar.es/en/), and they appreciate the financial support received from the projects ECO2014-54760 (MICINN, FEDER), and S09-PM062 (Gobierno de Aragon and Fondo Social Europeo) as well as from the program "Ayudas a la Investigación en Ciencias Sociales, Fundación Ramón Areces”. They want to show their gratitude to the collaborating bank for providing the data for the analyses. The authors want to show their gratitude to Prof. Goldenberg, Prof. Lehmann, and the anonymous reviewer for the guidance, encouragement, comments and suggestions received during the review process. 


\title{
“Are multichannel customers really more valuable? An analysis of banking services”
}

\begin{abstract}
Conventional wisdom suggests that multichannel customers are more profitable. With a focus on goods, Kushwaha and Shankar (2013) demonstrate that it depends on the type of product purchased. Our study replicates their research by looking at the profit implications of multichannel customers in services (banking). Our research shows that fully multichannel customers (using all channels available) are not the most profitable for service firms. We find that concentrating the interactions through high-margin channels as well as using specific dualchannel combinations produce improvements in profitability.
\end{abstract}

Key-words: Multichannel customer management; Customer profitability; Banking services; Time series. 


\section{1.-Introduction}

Whether multichannel customers are really more profitable has become a central research question in marketing (Neslin et al. 2006). The study by Kushwaha and Shankar (2013) (K\&S) intends to provide an answer to this question in a product context. They begin with the notion that "across all product categories, multichannel customers have a higher monetary value of purchases than single-channel customers". This thesis is based on three main reasons: a) additional channels provide greater convenience value for customers, increasing their purchase frequency and accelerating purchases across multiple items and categories; b) multichannel providers may offer a wider assortment of products and therefore customers have multiple opportunities to buy and increase their spending; c) customers can combine the benefits that different channels provide to derive a higher value from them and, thus, increase spending. Based on an analysis of single (catalog-only or Internet-only) vs. multichannel preferences and their impact on sales across multiple catalog/online retailers and product categories, K\&S conclude that multichannel customers are not always more profitable: multichannel customers are more profitable for hedonic products, while (traditional) single-channel customers have a higher monetary value for low-risk products.

This study replicates K\&S’s research in a services context (banking). Compared with goods, we expect the nature of services (e.g., intangibility, simultaneity of production and consumption) to influence the way in which customer preferences for channels affect profitability: while an increase in the number of channels used in goods enhances profits by leading customers to purchase more frequently and spend more (Kumar and Venkatesan 2005; Venkatesan, Kumar, and Ravishanker 2007), using multiple channels in services may increase the cost to serve the customer, with negative implications for profitability. We expect the extent to which customers are more or less profitable using various channel combinations in services to depend on the nature of the specific channels used (high vs. low-margin channels) and on whether they promote more vs. less efficient interactions (substitution effect vs. augmentation effect, Campbell and Frei 2010).

\section{2.-Study}

\section{1.-Design}


The data used in our empirical tests were provided by a European bank that offers financial services (e.g. certificates of deposit, savings accounts, mortgages) to individual customers (B2C) and has a volume of activity of 100,000 million euros, with 3.3 million customers, 6,300 employees and 1,400 offices. We obtained a random sample of 1,000 customers from which we had complete transaction and balance data for multiple services and channels for a period of 24 months (from August 2009 to July 2011). This bank operates on four main channels: point-ofSales (POS) machines at retail shops and service providers, automatic teller machines (ATM), its own branches (BRANCH) and via internet (ONLINE). We categorized the bank's services into three main groups: ASSETS (savings, interest-bearing checking, investments, etc.), CREDIT (credit card, installment loan, mortgage, line of credit, etc), and SERVICES (debit card, insurance, etc).

The empirical problem we face is distinct from the one faced by K\&S, who had access to aggregate measures gathered for multiple products across a large sample of consumers, and relied on cross-sectional analyses, accounting for cross-sectional endogeneity with demographics as instrumental variables. In contrast, we rely on a panel of customers from one bank, which we track over 24 months. Therefore, we are able to account for endogeneity biases due to selection and other effects associated with unobservable heterogeneity more directly, by incorporating fixed effects into our model. Given that we have enough information to account for individual differences, our main preoccupation is with endogenous effects that might affect our results over time.

To test for the impact of channel use on profitability, we estimate the following cross-sectional time-series model:

$$
\begin{aligned}
& \text { MARGIN }_{i t}=\mu_{i}^{P}+u_{t}^{P}+\alpha^{C} B A L_{i t}^{C}+\alpha^{A} B A L_{i t}^{A}+\sum_{k} \beta_{k} C H A N N E L_{i k t}+\sum_{k} \gamma_{k}^{C} B A L_{i t}^{C} * \\
& \text { CHANNEL } L_{i k t}+\sum_{k} \gamma_{k}^{A} B A L_{i t}^{A} * C H A N N E L_{i k t}+\sum_{k} \sum_{k^{\prime}} \beta_{k k^{\prime}} C H A N N E L_{i k t} * C H A N N E L_{i k \prime}+ \\
& \sum_{k} \sum_{k^{\prime}} \sum_{k^{\prime \prime}} \beta_{k k^{\prime} k^{\prime \prime}} \text { CHANNEL } L_{i k t} * \text { CHANNEL } L_{i k^{\prime} t} * \text { CHANNEL } L_{i k^{\prime \prime} t}
\end{aligned}
$$

$M_{A R G I N}{ }_{i t}=$ Sum of gross margin for financial and non-financial products plus fees for customer $i$ during month $t$ 
$\mu_{i}^{P}=$ fixed profitability (margin) effect for each customer $i$, accounting for endogenous crosssectional effects.

$\mu_{t}^{P}=$ fixed profitability (margin) effect for each month $t$, accounting for seasonal and trend effects.

$B A L_{i t}^{C}=$ balance held by customer $i$ on credit services during month $t$

$B A L_{i t}^{A}=$ assets held by customer $i$ on deposit and investment services during month $t$. Balances are not relevant for the third category (SERVICES)

CHANNEL $L_{i k t}=$ number of times customer $i$ used channel $k$ during month $t$, with $\mathrm{k}=1,4$ capturing the use of Point-of-Sales, ATM, Branch and Online channels.

Equation (1) parses out the effect of (single and multiple) channel use on customer profitability, after accounting for individual differences, time trend and volume of funds. While this equation accounts for endogenous effects across customers, it does not take into consideration changes in channel use induced by managers' marketing effort. This marketing effort can be endogenous, as managers usually base their targeting on what they observe in their customer database. Thus, to correct for these endogenous effects, we estimated two additional equations measuring how the customers' channel use is affected by their exposure to marketing communications (Equation A1), and how this marketing effort is affected by the customer information managers observe (Equation A2). We provide details on these two equations and their results in the Appendix I. Appendix II provides information on the correlation matrix and descriptive statistics for the studied variables. Based on this information, we conclude collinearity is not an issue in our empirical application.

We estimated our three-equation model using a 3-stage process. In the first stage, we estimated Equation (A2) as a fixed-effects multi-level Poisson regression, with months nested under individual customers. These estimates were the basis for replacing $M K T G_{i t}$ in Equation (A1) with a measure of marketing effort adjusted for the bank managers' targeting decisions. This adjusted marketing effort is combined with other indicators in a multivariate generalized linear model, to adjust the observed use of the four channels (POS, ATM, Branch and Online) by each customer in the 24-month period. In the final stage, we combine the adjusted (for marketing effort) channel use with other factors believed to affect customer profitability, in a fixed-effects 
linear model explaining the contribution margin produced by each customer in the 23 months (the first month is lost due to the lagged effect in the marketing-effort model).

\section{2.-Results}

The results from Equation (1) (the main focus of this study) are shown in Table 1. We also estimated an OLS version of our proposed model. The results appear in Appendix III, and they are largely consistent with the results we obtain. These results indicate that customers with larger ASSET balances tend to be more profitable, as one would expect. On the other hand, customers with larger CREDIT balances tend to be less profitable, which seems unexpected. However, the economic crisis has resulted in a high default rate in the payment of loans, which together with the decreasing interest rates and the lower margins in credit cards can help explain this negative effect. We also included interactions between channel usage and balances in our model. The results show an increase in margin for customers with higher asset balances using POS and with higher credit balances using ATM, and a decrease in margin for customers with large credit balances using the online channel.

\section{TABLE 1 ABOUT HERE}

Because K\&S only considered two channels, they categorized channel use into single or dual use. In our case, we have four channels, and therefore look into each specific interaction among these four channels. We find that, after adjusting for the endogenous nature of marketing effort and for selection bias, only POS and BRANCH channels have a statistically significant marginal impact on customer profitability. While ATM by itself does not have a statistically-significant effect, using both ATM and BRANCH leads to an increase in profitability. The same positive interaction is observed for POS and BRANCH. On the other hand, we find that using all four channels produces a negative marginal effect on profits. We compute the absolute effect (main plus interactions) of channel usage on margin for all combinations of channels in Table 2. The results indicate that while fully multichannel customers are profitable for the bank, they are outperformed by customers using three-channel combinations (e.g. branch, POS and online), and are almost equally profitable as customers using only two channels (branch and POS), after accounting for estimation errors. Taken together, after controlling for selection and endogeneity biases and accounting for various sources of individual differences, the analyses demonstrate 
that, while some single channel use and dual-channel combinations contribute to increase customer profitability, using all channels of the bank produces a decrease in profits.

\section{TABLE 2 ABOUT HERE}

\section{3.-Discussion and conclusions}

Contrary to conventional wisdom, K\&S demonstrate that multichannel customers are not always more profitable. Our analysis of the banking services industry offers additional support to K\&S's main thesis. We find that fully multichannel customers are not the most profitable for service firms because using all four channels of the bank leads to a decrease in profits. We also find that concentrating all the interactions through some single channels (branch or POS) as well as using specific dual-channel combinations (branch and ATM; branch and POS) produces improvements in margin, and that the combination of branch, POS and the Internet has the largest total impact on profits. However, in services operations, channel use may change monthly and, thus, the longterm profitability and CLV of customers should account for these variations in channel usage over time.

The results obtained can be explained based on the nature of specific channels used (high vs. low-margin channels) and on whether they promote more vs. less efficient interactions (substitution effect vs. augmentation effect, Campbell and Frei 2010). With regard to the significant effects of single-channel usage on profits, the positive marginal impact of branch banking on customer profitability is due to the fact that customers tend to use this channel for large and important transactions that are often associated with transaction fees (high margin channel). Importantly, this face-to-face channel also helps promote cross-buying and the purchase of higher margin services. Therefore, a larger number of interactions through this channel provides opportunities to develop stronger relationships with high-value customers and improve customer profits. Similarly, using the POS, which provides a higher margin for the bank (because the bank collects a fee from the retailer for each use), significantly contributes to increase the customer profit. About the dual-channel combinations, using the branch and the ATM produces an increase in profit, which is likely due to a substitution effect that enables customers to migrate some routine operations from relatively more costly channels (e.g. the branch or POS) to the ATM (Campbell and Frei 2010), thus producing more efficient interactions between the bank and its customers without compromising the quality of the 
relationship. Similarly, as expected, combining the branch and the POS leads to increased profits, as these two channels produce margins that are significantly higher than those of the other channels. In contrast, using all channels produces a negative marginal effect on profits. This is probably due to an augmentation effect, in which customers usage of multiple channels, some of them highly convenient (e.g. online), leads to an increase in the demand for services (e.g. requests, information), which in turn produces an increase in the cost to serve the customer while not leading to a significant improvement in the relationship. Interestingly, the results show no significant effect of using the online channel on profits either used alone (single-channel) or in combination with one or two more channels. While the online channel is the least costly, prior research shows that, at least in services, the use of this channel may not produce positive effects on performance (Campbell and Frei 2010) as it (i) prevents building close and successful relationships with valuable customers, (ii) is limited in its ability to promote cross-buying of additional, higher-margin, products and services, (iii) makes it easier to switch service providers, and, in a banking context, (iv) facilitates information monitoring and promotes more active account management.

In conclusion, our study replicates $\mathrm{K} \& \mathrm{~S}$ in a service setting demonstrating that multichannel customers are not always the most profitable. We extend K\&S's findings by noting that while using all channels of the bank reduces customer profits, there are some dual and three-channel combinations that produce improvements in customer profitability. The insights derived from K\&S combined with our study findings can contribute to a better understanding of the profitability implications of customer channel usage (Verhoef, Kannan, and Inman 2015). 


\section{REFERENCES}

Campbell, D. \& Frei, F. (2010). Cost structure, customer profitability, and retention implications of self-service distribution channels: Evidence from customer behavior in an online banking channel. Management Science, Vol. 56 (1), 4-24.

Kumar, V. \& Venkatesan, R. (2005). Who are multichannel shoppers and how do they perform? Correlates of multichannel shopping behaviour. Journal of Interactive Marketing, Vol. 19 (2), 44-61.

Kushwaha, T., Shankar, V. (2013): “Are multichannel customers really more valuable? The moderating role of product category characteristics”. Journal of Marketing, Vol. 77 (4), 67-85.

Neslin, S., Grewal, D., Leghorn, R., Shankar, V., Teerling, M., Thomas, J., \& Verhoef, P. (2006). Challenges and opportunities in multichannel customer management. Journal of Service Research, Vol. 9 (2), 95-112.

Venkatesan, R., Kumar, V., \& Ravishanker, N. (2007). Multichannel shopping: Causes and consequences. Journal of Marketing, Vol. 71 (2), 114-32.

Verhoef, P., Kannan, P., Inman, J., (2015): "From multi-channel retailing to omni-channel retailing: introduction to the special issue on multi-channel retailing”. Journal of Retailing, Vol. 91 (2), pp. 174-181. 
Table 1 - Estimates for the final Fixed-effects Regression model for Contribution Margin

\begin{tabular}{|c|c|c|}
\hline \multirow[b]{2}{*}{ Predictors } & \multicolumn{2}{|c|}{$\begin{array}{l}\text { With Endogeneity } \\
\text { Corrections }\end{array}$} \\
\hline & Beta & Significance \\
\hline \multicolumn{3}{|l|}{ Balances } \\
\hline $\mathrm{BAL}^{\mathrm{A}}{ }_{\mathrm{it}}$ & 0.116 & 0.000 \\
\hline $\mathrm{BAL}^{\mathrm{C}}{ }_{\text {it }}$ & -0.029 & 0.000 \\
\hline \multicolumn{3}{|l|}{ Channel Use } \\
\hline POS & 0.048 & 0.000 \\
\hline ATM & -0.010 & 0.129 \\
\hline BRANCH & 0.040 & 0.000 \\
\hline ONLINE & 0.000 & 0.987 \\
\hline ATM*BRANCH & 0.017 & 0.003 \\
\hline ATM*ONLINE & -0.002 & 0.718 \\
\hline POS*ATM & -0.002 & 0.706 \\
\hline BRANCH*ONLINE & 0.000 & 0.949 \\
\hline POS*BRANCH & 0.018 & 0.006 \\
\hline POS*ONLINE & 0.009 & 0.113 \\
\hline ATM*BRANCH*ONLINE & -0.002 & 0.548 \\
\hline POS*ATM*BRANCH & 0.000 & 0.997 \\
\hline POS*ATM*ONLINE & -0.001 & 0.735 \\
\hline POS*BRANCH*ONLINE & -0.003 & 0.570 \\
\hline POS*ATM*BRANCH*ONLINE & -0.005 & 0.005 \\
\hline \multicolumn{3}{|c|}{ Interaction: Balance * Channel Use } \\
\hline $\mathrm{BAL}^{\mathrm{A}_{\mathrm{it}}} * \mathrm{POS}$ & 0.015 & 0.008 \\
\hline $\mathrm{BAL}^{\mathrm{A}}{ }_{\mathrm{it}} * \mathrm{ATM}$ & -0.005 & 0.387 \\
\hline $\mathrm{BAL}^{\mathrm{A}}{ }_{\mathrm{it}} * \mathrm{BRANCH}$ & -0.009 & 0.120 \\
\hline $\mathrm{BAL}^{\mathrm{A}}{ }_{\mathrm{it}}{ }^{*}$ ONLINE & -0.003 & 0.561 \\
\hline $\mathrm{BAL}^{\mathrm{C}}{ }_{\mathrm{it}} * \mathrm{POS}$ & 0.002 & 0.742 \\
\hline $\mathrm{BAL}^{\mathrm{C}}{ }_{\mathrm{it}} * \mathrm{ATM}$ & 0.021 & 0.011 \\
\hline $\mathrm{BAL}^{\mathrm{C}}{ }_{\mathrm{it}}{ }^{*} \mathrm{BRANCH}$ & 0.003 & 0.745 \\
\hline $\mathrm{BAL}^{\mathrm{C}}{ }_{\mathrm{it}}{ }^{*} \mathrm{ONLINE}$ & -0.017 & 0.032 \\
\hline Adjusted $\mathrm{R}^{2}$ & & 183 \\
\hline
\end{tabular}


Table 2 - Total impact of every channel combination on profitability

\begin{tabular}{|c|c|c|}
\hline Channel use & Total Effect & Std. Error \\
\hline \multicolumn{3}{|l|}{ Single-channel use } \\
\hline POS & 0.048 & 0.007 \\
\hline ATM & -0.010 & 0.007 \\
\hline BRANCH & 0.040 & 0.007 \\
\hline ONLINE & 0.000 & 0.007 \\
\hline \multicolumn{3}{|l|}{ Dual-channel use } \\
\hline ATM*BRANCH & 0.046 & 0.0115 \\
\hline ATM*ONLINE & -0.013 & 0.0110 \\
\hline POS*ATM & 0.035 & 0.0110 \\
\hline BRANCH*ONLINE & 0.040 & 0.0115 \\
\hline POS*BRANCH & 0.105 & 0.0115 \\
\hline POS*ONLINE & 0.057 & 0.0115 \\
\hline \multicolumn{3}{|l|}{ Three-channel use } \\
\hline ATM*BRANCH*ONLINE & 0.043 & 0.0156 \\
\hline POS*ATM*BRANCH & 0.110 & 0.0156 \\
\hline POS*ATM*ONLINE & 0.041 & 0.0152 \\
\hline POS*BRANCH*ONLINE & 0.112 & 0.0159 \\
\hline \multicolumn{3}{|l|}{ Four-channel use } \\
\hline POS*ATM*BRANCH*ONLINE & 0.106 & 0.0212 \\
\hline
\end{tabular}




\section{“Are multichannel customers really more valuable? An analysis of banking services"}

\section{APPENDIX I: Details on the econometric model}

Here we explain in detail Equations A1 and A2 (and their estimation results), which help account for potential endogeneity biases.

As noted previously, Equation A1 measures how the customers' channel use can be affected by their exposure to marketing communications from the bank:

$C_{H A N N E L_{I k t}}=\mu_{i k}^{C}+\varphi_{k} D E M O_{i}+\delta^{A} A C C N T_{i t}^{A}+\delta^{C} A C C N T_{i t}^{C}+\delta^{S} A C C N T_{i t}^{S}+\omega_{k} M K T G_{i t}$

where,

CHANNEL $L_{i k t}=$ number of times customer $i$ used channel $k$ during month $t$, with $\mathrm{k}=1,4$ capturing the use of Point-of-Sales, ATM, Branch and Online channels.

$\mu_{i k}^{C}=$ fixed effect for each customer $i$, and channel $k$ accounting for endogenous cross-sectional effects in channel use.

$D E M O_{i}=$ vector containing the demographic profile of customer $i$, accounting for customer-level effects beyond the fixed effect, such as demographic targeting implemented by management. $\operatorname{ACCNT}_{i t}^{A}=$ number of asset (e.g., checking, savings, investment) accounts held by customer $i$ during month $t$

$A C C N T_{i t}^{C}=$ number of credit accounts (e.g., loans, credit card, mortgage) held by customer $i$ during month $t$

$A C C N T_{i t}^{S}=$ number of service accounts (insurance, debit card) held by customer $i$ during month $t$ $M K T G_{i t}=$ marketing effort targeted towards customer ii during month $t$, to account for the possibility that channel use by customer $i$ may vary over time in response to marketing communications. 
While Equation (A1) above helps to account for customers' response to marketing communications, we must consider that managers make an effort to target their marketing efforts to specific customers, based on what they observe in their customer database. In other words, this marketing effort is also endogenous. Therefore, we attempt to capture the managers' targeted outbound customer contacts to what managers observe and may use to focus their efforts in the next month. We do this via the following equation:

$M K T G_{i t}=\mu_{i}^{M}+\theta^{C} B A L_{i t-1}^{C}+\theta^{A} B A L_{i t-1}^{A}+\gamma \operatorname{COST}_{i t-1}+\tau T E N U R E_{i t-1}$

where,

$M K T G_{i t}=$ marketing effort, measured as the number of contacts initiated by the bank, targeted towards customer $i$ during month $t$

$\mu_{i}^{M}=$ fixed marketing effect for each customer $i$, accounting for endogenous cross-sectional effects.

$B A L_{i t-1}^{C}=$ balance held by customer $i$ on credit services during month $t-1$

$B A L_{i t-1}^{A}=$ assets held by customer $i$ on deposit and investment services during month $t-1$ $\operatorname{COST}_{i t-1}=$ Cost of servicing customer $i$ during period $t-1$

$T E N U R E_{i t-1}=$ Customer $i$ 's tenure in months up to period $t-1$.

As noted, we estimated the three-equation model using a 3-stage process. In the first stage, we estimated Equation (A2), as a fixed-effects multi-level Poisson regression, with months nested under individual customers. We used a Poisson regression because of the limited number of contacts observed each month for each customer. These estimates are shown in Table A.1 (estimates of the 999 customer fixed effects are not reported, due to space limitations). These estimates indicate that the bank is more likely to contact recently-acquired customers who are less costly to serve. The bank is also more likely to contact customers who hold large balance in ASSET accounts.

\section{TABLE A.1 ABOUT HERE}

In Equation (A1), marketing effort adjusted for the bank managers' targeting decisions (Equation A2) is combined with other indicators in a multivariate generalized linear model. The estimates (reflecting the relative contribution of each predictor) from this stage are reported in Table A.2. 


\section{TABLE A.2 ABOUT HERE}

Table A.2 indicates that, beyond the customer-level fixed effects (utilized to correct for selection biases), the only demographic characteristics that affects channel use is age; older customers are heavier users of POS, ATM and BRANCH. Direct Marketing communications has a statistically significant impact only on the use of BRANCH and ONLINE banking. This suggests that the bank's managers are effective in inducing some customers (probably the most valuable ones) towards branch banking and others to online banking. Moreover, the relative contribution of marketing effort in explaining use of these two channels is reasonably high, when compared to the other predictors. 
Table A.1 - Estimates for the Poisson Regression model for Marketing Effort

\begin{tabular}{|l|c|c|c|}
\hline \multicolumn{1}{|c|}{ Predictor } & Estimate & Std. Error & Significance \\
\hline COST $_{\text {it-1 }}$ & $-\mathbf{- 7 . 4 3 E - 0 4}$ & $3.41 \mathrm{E}-04$ & 0.000 \\
\hline TENURE $_{\text {it-1 }}$ & $\mathbf{- 1 . 5 6 E - 0 4}$ & $4.36 \mathrm{E}-05$ & 0.000 \\
\hline BAL $^{{ }_{\text {it-1 }}}$ & $\mathbf{1 . 2 7 E - 0 6}$ & $4.32 \mathrm{E}-07$ & 0.000 \\
\hline BAL $^{{ }_{\text {it-1 }}}$ & $-1.28 \mathrm{E}-06$ & $1.18 \mathrm{E}-06$ & 0.537 \\
\hline
\end{tabular}

$L L=-15230 ; A I C=32469 ; \quad B I C=40544$ 
Table A.2 - Estimates for the fixed-effects Generalized Linear Model for Channel Use

\begin{tabular}{|c|c|c|c|c|c|c|c|c|}
\hline \multirow[b]{2}{*}{ Predictor } & \multicolumn{2}{|c|}{ POS } & \multicolumn{2}{|c|}{ ATM } & \multicolumn{2}{|c|}{ BRANCH } & \multicolumn{2}{|c|}{ ONLINE } \\
\hline & Beta & Significance & Beta & Significance & Beta & Significance & Beta & Significance \\
\hline Age (years) & 0.001 & 0.026 & 0.001 & 0.021 & 0.001 & 0.007 & 0.000 & 0.109 \\
\hline Male (dummy) & -0.001 & 0.949 & -0.001 & 0.947 & -0.001 & 0.939 & 0.000 & 0.964 \\
\hline Education (years) & 0.001 & 0.428 & 0.001 & 0.411 & 0.001 & 0.340 & 0.000 & 0.569 \\
\hline Urban (dummy) & -0.001 & 0.930 & -0.001 & 0.928 & -0.001 & 0.916 & 0.000 & 0.950 \\
\hline Married (dummy) & -0.009 & 0.415 & -0.011 & 0.398 & -0.015 & 0.327 & -0.005 & 0.558 \\
\hline Low income & -0.001 & 0.929 & -0.001 & 0.927 & -0.002 & 0.915 & -0.001 & 0.949 \\
\hline Medium-low income & -0.002 & 0.888 & -0.003 & 0.884 & -0.004 & 0.865 & -0.001 & 0.919 \\
\hline Medium-high income & -0.003 & 0.868 & -0.003 & 0.863 & -0.005 & 0.842 & -0.001 & 0.905 \\
\hline High income & -0.001 & 0.977 & -0.001 & 0.976 & -0.001 & 0.972 & 0.000 & 0.983 \\
\hline ACCNT $^{\mathrm{S}}$ it (adjusted) & 0.129 & 0.000 & 0.108 & 0.000 & -0.027 & 0.045 & 0.059 & 0.000 \\
\hline ACCNT $_{\text {it }}$ (adjusted) & 0.042 & 0.000 & -0.014 & 0.158 & -0.026 & 0.026 & 0.011 & 0.083 \\
\hline ACCNT $^{\mathrm{A}}$ it (adjusted) & 0.017 & 0.010 & 0.027 & 0.000 & 0.039 & 0.000 & 0.011 & 0.011 \\
\hline MKTG $_{\text {it }}$ (adjusted) & 0.000 & 0.941 & 0.008 & 0.161 & 0.050 & 0.000 & 0.021 & 0.000 \\
\hline Adjusted $\mathrm{R}^{2}$ & \multicolumn{2}{|c|}{0.009} & \multicolumn{2}{|c|}{$\frac{1}{0.005}$} & \multicolumn{2}{|c|}{0.004} & \multicolumn{2}{|c|}{$\frac{1}{0.006}$} \\
\hline
\end{tabular}




\section{APPENDIX II: Descriptive statistics and correlation matrix}

\begin{tabular}{|c|c|c|c|c|c|c|c|c|c|c|c|c|c|c|c|c|c|c|c|c|c|c|c|c|c|c|}
\hline Var & 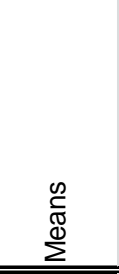 & 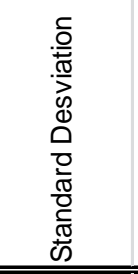 & 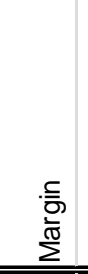 & $\begin{array}{l}0 \\
0 \\
0 \\
00 \\
0 \\
\end{array}$ & $\begin{array}{l}\text { 픙 } \\
\text { d } \\
\text { U }\end{array}$ & $\begin{array}{l}\sim \\
\text { O } \\
\Sigma \\
\end{array}$ & 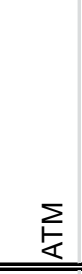 & 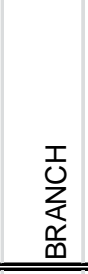 & $\begin{array}{l}\text { 崩 } \\
⿱ 亠 䒑 \\
\mathrm{Z} \\
\end{array}$ & 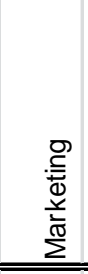 & 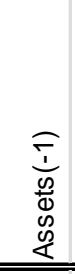 & 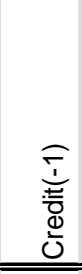 & 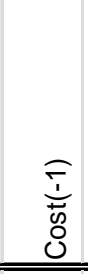 & 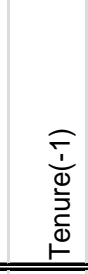 & 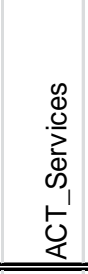 & 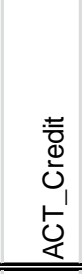 & 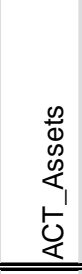 & 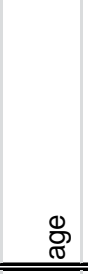 & $\frac{\frac{0}{\pi}}{\Sigma}$ & 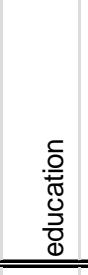 & 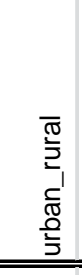 & 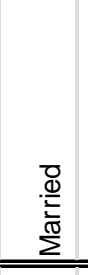 & 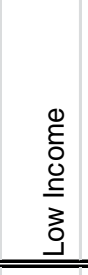 & 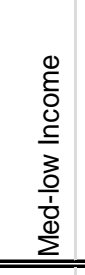 & 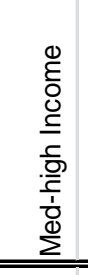 & 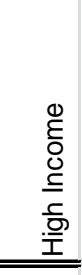 \\
\hline Margin & 67.27 & 131.78 & 1.00 & 0.07 & 0.05 & 0.05 & -0.02 & \begin{tabular}{|c|}
-0.01 \\
\end{tabular} & 0.02 & 0.02 & 0.05 & 0.04 & 0.04 & -0.17 & 0.02 & 0.06 & 0.06 & -0.01 & 0.00 & 0.00 & 0.00 & 0.00 & 0.00 & 0.00 & 0.00 & 0.00 \\
\hline ssets & 71793.3 & 95982.79 & 0.07 & 1.00 & -0.01 & 0.06 & 0.06 & 0.08 & 0.05 & 0.02 & 0.38 & 0.08 & 0.03 & 0.10 & 0.04 & 0.02 & 0.31 & 0.01 & 0.00 & 0.00 & 0.00 & 0.00 & 0.00 & 0.00 & 0.00 & 0.00 \\
\hline Credit & 898.8 & 52635.47 & 0.05 & -0.01 & 1.00 & 0.02 & -0.08 & -0.11 & -0.07 & -0.02 & 0.06 & 0.29 & 0.07 & -0.26 & 0.04 & 0.41 & 0.05 & -0.01 & 0.00 & 0.00 & 0.00 & 0.00 & 0.00 & 0.00 & 0.00 & 0.00 \\
\hline POS & 00 & 520 & 0.05 & 0.06 & 0.02 & 1.00 & 0.30 & 0.13 & 0.14 & -0.01 & 0.04 & 0.03 & 0.01 & 0.18 & 0.08 & 0.04 & 0.02 & 0.01 & 0.00 & 0.00 & 0.00 & 0.00 & 0.00 & 0.00 & 0.00 & 0.00 \\
\hline 101 & 2.12 & .40 & -0.02 & 0.06 & -0.08 & 0.30 & 1.00 & 0.17 & 0.11 & 0.01 & 0.05 & 0.01 & 0.01 & 0.20 & 0.06 & 0.00 & 0.03 & 0.01 & 0.00 & 0.00 & 0.00 & 0.00 & 0.00 & 0.00 & 0.00 & 0.00 \\
\hline BRANCH & 66 & 7.51 & -0.01 & 0.08 & -0.11 & 0.13 & 0.17 & 1.00 & 0.13 & 0.06 & 0.02 & -0.01 & -0.02 & 0.22 & -0.01 & -0.01 & 0.03 & 0.02 & 0.00 & 0.00 & 0.00 & 0.00 & 0.00 & 0.00 & 0.00 & 0.00 \\
\hline ONLINE & 5.5 & 22.83 & 0.02 & 0.05 & -0.07 & 0.14 & 0.11 & 0.13 & 1.00 & 0.05 & 0.04 & 0.01 & 0.01 & 0.13 & 0.06 & 0.02 & 0.02 & 0.01 & 0.00 & 0.00 & 0.00 & 0.00 & 0.00 & 0.00 & 0.00 & 0.00 \\
\hline Marketing & 0.35 & 0.69 & 0.02 & 02 & -0.02 & -0.01 & 0.01 & 0.06 & 0.05 & 1.00 & 0.02 & 0.00 & -0.02 & -0.02 & 0.01 & 0.01 & 0.00 & 0.00 & 0.00 & 0.00 & 0.00 & 0.00 & 0.00 & 0.00 & 0.00 & 0.00 \\
\hline Assets(-1) & 2.39 & 21755.55 & 0.05 & 0.38 & 0.06 & 0.04 & 0.05 & 0.02 & 0.04 & 0.02 & 1.00 & 0.29 & 0.09 & 0.08 & 0.00 & 0.04 & 0.26 & 0.01 & 0.00 & 0.00 & 0.00 & 0.00 & 0.00 & 0.00 & 0.00 & 0.00 \\
\hline Crec & .37 & 10559.01 & 0.04 & 0.08 & 0.29 & 0.03 & 0.01 & -0.01 & 0.01 & 0.00 & 0.29 & 1.00 & 0.05 & -0.03 & 0.04 & 0.23 & 0.07 & 0.00 & 0.01 & 0.00 & -0.01 & 0.01 & 0.00 & 0.00 & 0.00 & 0.00 \\
\hline $\operatorname{Cost}(-1)$ & -0.55 & 27.32 & 0.04 & 0.03 & 0.07 & 0.01 & 0.01 & -0.02 & 0.01 & -0.02 & 0.09 & 0.05 & 1.00 & 0.00 & 0.00 & 0.07 & 0.05 & 0.01 & -0.01 & -0.01 & -0.01 & 0.00 & -0.01 & -0.01 & 0.00 & 0.00 \\
\hline Tenur & .71 & 67 & -0.17 & 0.10 & -0.26 & 0.18 & 0.20 & 0.22 & 0.13 & -0.02 & 0.08 & -0.03 & 0.00 & 1.00 & -0.02 & -0.08 & -0.01 & 0.04 & -0.01 & 0.00 & 0.00 & 0.00 & -0.01 & 0.00 & 0.00 & 0.00 \\
\hline ACT_Services & 0 . & 02 & 0.02 & 0.04 & 0.04 & 0.08 & 0.06 & -0.01 & 0.06 & 0.01 & 0.00 & 0.04 & 0.00 & -0.02 & 1.00 & 0.05 & 0.05 & 0.00 & 0.00 & 0.00 & 0.00 & 0.00 & 0.00 & 0.00 & 0.00 & 0.00 \\
\hline ACT_Credit & 3.64 & 3.06 & 0.06 & 0.02 & 0.41 & 0.04 & 0.00 & -0.01 & 0.02 & 0.01 & 0.04 & 0.23 & 0.07 & -0.08 & 0.05 & 1.00 & 0.05 & 0.00 & 0.00 & 0.00 & 0.00 & 0.00 & 0.00 & 0.00 & 0.00 & 0.00 \\
\hline ACT_Assets & 0.77 & 0.98 & 0.06 & 0.31 & 0.05 & 0.02 & 0.03 & 0.03 & 0.02 & 0.00 & 0.26 & 0.07 & 0.05 & -0.01 & 0.05 & 0.05 & 1.00 & 0.00 & 0.00 & 0.00 & 0.00 & 0.00 & 0.00 & 0.00 & 0.00 & 0.00 \\
\hline age & 51.48 & 14.06 & -0.01 & 0.01 & -0.01 & 0.01 & 0.01 & 0.02 & 0.01 & 0.00 & 0.01 & 0.00 & 0.01 & 0.04 & 0.00 & 0.00 & 0.00 & 1.00 & 0.03 & -0.38 & 0.08 & 0.40 & 0.00 & 0.03 & 0.02 & 0.00 \\
\hline Male & 0.59 & 0.492 & 0.00 & 0.00 & 0.00 & 0.00 & 0.00 & 0.00 & 0.00 & 0.00 & 0.00 & 0.01 & -0.01 & -0.01 & 0.00 & 0.00 & 0.00 & 0.03 & 1.00 & 0.01 & -0.03 & 0.02 & 0.06 & 0.00 & -0.06 & 0.03 \\
\hline education & 10.81 & 5.546 & 0.00 & 0.00 & 0.00 & 0.00 & 0.00 & 0.00 & 0.00 & 0.00 & 0.00 & 0.00 & -0.01 & 0.00 & 0.00 & 0.00 & 0.00 & -0.38 & 0.01 & 1.00 & -0.11 & -0.16 & -0.02 & 0.05 & 0.05 & 0.09 \\
\hline urban_rural & 1.22 & 0.65 & 0.00 & 0.00 & 0.00 & 0.00 & 0.00 & 0.00 & 0.00 & 0.00 & 0.00 & -0.01 & -0.01 & 0.00 & 0.00 & 0.00 & 0.00 & 0.08 & -0.03 & -0.11 & 1.00 & 0.04 & -0.04 & 0.00 & -0.03 & -0.01 \\
\hline Married & 0.71 & 0.45 & 0.00 & 0.00 & 0.00 & 0.00 & 0.00 & 0.00 & 0.00 & 0.00 & 0.00 & 0.01 & 0.00 & 0.00 & 0.00 & 0.00 & 0.00 & 0.40 & 0.02 & -0.16 & 0.04 & 1.00 & 0.00 & 0.02 & -0.03 & 0.11 \\
\hline Low Income & 0.42 & 0.49 & 0.00 & 0.00 & 0.00 & 0.00 & 0.00 & 0.00 & 0.00 & 0.00 & 0.00 & 0.00 & -0.01 & -0.01 & 0.00 & 0.00 & 0.00 & 0.00 & 0.06 & -0.02 & -0.04 & 0.00 & 1.00 & -0.30 & -0.28 & -0.24 \\
\hline Med-low Income & 0.11 & 0.31 & 0.00 & 0.00 & 0.00 & 0 & 0 & 0 & 0.00 & 0.00 & 0 & 0 & -0.01 & 00 & 0 & 0 & 00 & 03 & 0.00 & 0.05 & 0.00 & 0.02 & -0.30 & 1.00 & -0.12 & -0.10 \\
\hline Med-high Income & 0.1 & 0.29 & 0.00 & 0.00 & 0.00 & 00 & 0.00 & 0.00 & 0.00 & 0.00 & 0.00 & 0.00 & 0.00 & 0.00 & 0.00 & 0.00 & 0.00 & .02 & -0.06 & 0.05 & -0.03 & -0.03 & -0.28 & -0.12 & 1.00 & -0.09 \\
\hline High Income & 0.07 & 6 & 0.00 & 0.00 & 0.00 & 0.00 & 0.00 & 0.00 & 0.00 & 0.00 & 0.00 & 0.00 & 0.00 & 0.00 & 0.00 & 0.00 & 0.00 & 0.00 & 0.03 & 0.09 & -0.01 & 0.11 & -0.24 & -0.10 & -0.09 & 1.00 \\
\hline
\end{tabular}




\section{APPENDIX III: OLS estimation}

Table A.3 - Estimates for the OLS model

\begin{tabular}{|c|c|c|}
\hline \multirow[b]{2}{*}{ Predictors } & \multicolumn{2}{|c|}{ Without Corrections } \\
\hline & Beta & Significance \\
\hline \multicolumn{3}{|l|}{ Balances } \\
\hline $\mathrm{BAL}^{\mathrm{A}} \mathrm{it}_{\mathrm{t}}$ & 0.000 & 0.004 \\
\hline $\mathrm{BAL}^{\mathrm{C}}{ }_{\text {it }}$ & 0.000 & 0.634 \\
\hline \multicolumn{3}{|l|}{ Channel Use } \\
\hline POS & 0.022 & 0.031 \\
\hline ATM & -0.002 & 0.832 \\
\hline BRANCH & 0.028 & 0.004 \\
\hline ONLINE & -0.018 & 0.162 \\
\hline ATM*BRANCH & -0.001 & 0.878 \\
\hline ATM*ONLINE & -0.009 & 0.224 \\
\hline POS*ATM & -0.003 & 0.408 \\
\hline BRANCH*ONLINE & -0.003 & 0.639 \\
\hline POS*BRANCH & -0.001 & 0.677 \\
\hline POS*ONLINE & -0.004 & 0.567 \\
\hline ATM*BRANCH*ONLINE & -0.002 & 0.319 \\
\hline POS*ATM*BRANCH & -0.000 & 0.842 \\
\hline POS*ATM*ONLINE & 0.006 & 0.002 \\
\hline POS*BRANCH*ONLINE & 0.0004 & 0.852 \\
\hline POS*ATM*BRANCH*ONLINE & 0.001 & 0.029 \\
\hline \multicolumn{3}{|l|}{ Interaction: Balance * Channel Use } \\
\hline $\mathrm{BAL}^{\mathrm{A}} \mathrm{it} * \mathrm{POS}$ & 0.000 & 0.275 \\
\hline $\mathrm{BAL}^{\mathrm{A}}$ it $*$ ATM & 0.000 & 0.125 \\
\hline $\mathrm{BAL}^{\mathrm{A}}$ it ${ }^{*} \mathrm{BRANCH}$ & 0.000 & 0.000 \\
\hline $\mathrm{BAL}^{\mathrm{A}}{ }_{\mathrm{it}} *$ ONLINE & 0.000 & 0.193 \\
\hline $\mathrm{BAL}^{\mathrm{C}}{ }_{\mathrm{it}} * \mathrm{POS}$ & 0.000 & 0.000 \\
\hline $\mathrm{BAL}^{\mathrm{C}}{ }_{\mathrm{it}} * \mathrm{ATM}$ & 0.000 & 0.127 \\
\hline $\mathrm{BAL}^{\mathrm{C}}{ }_{\mathrm{it}} * \mathrm{BRANCH}$ & 0.000 & 0.759 \\
\hline $\mathrm{BAL}^{\mathrm{C}}{ }_{\mathrm{it}}{ }^{*}$ ONLINE & 0.000 & 0.000 \\
\hline Adjusted $\mathrm{R}^{2}$ & & \\
\hline
\end{tabular}


Table A.4 - Total impact of every channel combination on profitability based on OLS results

\begin{tabular}{|l|c|c|}
\hline Channel use & Total Effect & Std. Error \\
\hline Single-channel use & 0.022 & 0.010 \\
\hline POS & -0.002 & 0.010 \\
\hline ATM & 0.028 & 0.009 \\
\hline BRANCH & -0.018 & 0.013 \\
\hline ONLINE & 0.025 & 0.015 \\
\hline Dual-channel use & -0.029 & 0.018 \\
\hline ATM*BRANCH & 0.017 & 0.015 \\
\hline ATM*ONLINE & 0.007 & 0.017 \\
\hline POS*ATM & 0.049 & 0.014 \\
\hline BRANCH*ONLINE & 0.000 & 0.018 \\
\hline POS*BRANCH & -0.007 & 0.022 \\
\hline POS*ONLINE & 0.015 & 0.018 \\
\hline Three-channel use & -0.008 & 0.022 \\
\hline ATM*BRANCH*ONLINE & 0.024 & 0.021 \\
\hline POS*ATM*BRANCH & \\
\hline POS*ATM*ONLINE & 0.014 & 0.026 \\
\hline POS*BRANCH*ONLINE & \\
\hline Four-channel use &
\end{tabular}

